Motrivivência Ano XXV, No 41, P. 258-268 Dez./2013

http://dx.doi.org/10.5007/2175-8042.2013v25n41p258

\title{
RELATOS E MEMÓRIAS DOS MORADORES DE RUA: estudos sobre qualidade de vida, políticas públicas $E$ LAZER para a população em situação de Rua da Cidade de Criciúma/SC
}

Clarissa Mariano Rocha'

Carlos Augusto Euzébio²

"Não somos lixo.

Não somos lixo e nem bicho.

Somos humanos.

Se na rua estamos é porque nos desencontramos.

Não somos bicho e nem lixo.

Nós somos anjos, não somos o mal.

Nós somos arcanjos no juízo final.

Nós pensamos e agimos, calamos e gritamos.

Ouvimos o silêncio cortante dos que afirmam serem santos.

Não somos lixo.

Será que temos alegria? Às vezes sim...

Temos com certeza o pranto, a embriaguez,

A lucidez dos sonhos da filosofia.

Não somos profanos, somos humanos.

Somos filósofos que escrevem

Suas memórias nos universos diversos urbanos.

A selva capitalista joga seus chacais sobre nós.

Não somos bicho nem lixo, temos voz.

Por dentro da caótica selva, somos vistos como fantasmas.

Existem aqueles que se assustam.

Não somos mortos, estamos vivos.

Andamos em labirintos.

Depende de nossos instintos.

Somos humanos nas ruas, não somos lixo."

(Carlos Eduardo - Morador de rua - Salvador).

1 Licenciada em Educação Física pela UNESC. Criciúma/Santa Catarina, Brasil.

E-mail: clarissamariano@gmail.com

2 Mestre em Educação. Professor da UNESC. Criciúma/Santa Catarina, Brasil.

E-mail: cae@unesc.net 


\section{RESUMO}

Este trabalho trata da situação de quem se encontra na condição de moradores de rua. Organizou-se uma abordagem qualitativa fundamentada na revisão bibliográfica que buscou discutir a qualidade de vida e políticas públicas relacionadas aos moradores de rua. Foram realizadas entrevistas com moradores de rua com o intuito de compreender qual é a qualidade de vida dos moradores de rua. Por perderem laços familiares, empregos e tantos outros motivos como drogas, alcoolismo, discriminação social, dignidade, esta população utiliza das ruas como moradia e abrigo.

Palavras-chave: Moradores de rua; Qualidade de vida;Políticas públicas.

\section{INTRODUÇÃO}

O capitalismo como o próprio nome deixa claro, é um sistema que se baseia no acumulo de capital, a partir disso surgem Às classes sociais e as relações de trabalho. A sociedade se divide entre a burguesia que detém os meios de produção e o proletariado que possui somente sua força de trabalho. Dessa forma, a sociedade se divide entre exploradores e explorados, ou seja, exploração do homem pelo homem. No capitalismo, a sociedade burguesa aceita como fato natural jogar milhões de pessoas na miséria para seu enriquecimento. (LESSA; TONET, 2004).

A lógica capitalista (do lucro), inevitavelmente produz desigualdades sociais, pois nem todos têm condições de deter os meios de produção. Percebem-se obrigados a vender sua força de trabalho em troca de salário e sobrevivem do trabalho assalariado. Na pirâmide que o capitalismo cria, nem todas as pessoas conseguirão vender sua força de trabalho, assim, utiliza essa condição para conseguir manter e aprofundar a exploração daqueles que estão empregados.

Na mesma pirâmide, acumulam-se diversos problemas, pois nem todos terão acesso à saúde, educação, cultura e até ao mais básico, o direito à moradia.

Este trabalho trata da situação de quem se encontra na base dessa pirâmide, os moradores de rua. Para dar conta desta tarefa, primeiramente, organizou-se uma abordagem qualitativa fundamentada na revisão bibliográfica que buscou discutir a qualidade de vida e políticas públicas relacionadas aos moradores de rua. Após compreender teoricamente o assunto se elaborou as entrevistas semi abertas para os moradores de rua e um dos representantes do sistema social público que atende os grupos que se encontram em situação de vulnerabilidade e risco social em Criciúma-SC. Foram procurados moradores de rua nas praças, ruas e no albergue da cidade, solicitando a colaboração e autorização dos mesmos para a realização das entrevistas.

O problema foi estipulado a partir da seguinte pergunta: qual a qualidade de vida dos moradores de rua. As questões norteadoras foram estabelecidas a partir do problema da pesquisa tais como: qual a rotina dos moradores de rua?;os moradores de rua têm o objetivo de mudar sua situação social?; Os moradores de rua têm alguma assistência relacionada à qualidade 
de vida? Existem políticas públicas para os moradores de rua de Criciúma?

O objetivo geral consiste em compreender qual é a qualidade de vida dos moradores de rua.Como objetivos específicos,identificar qual a rotina dos moradores de rua; investigar se os moradores de rua têm o objetivo de mudar sua situação social;averiguar se os moradores de rua têm alguma assistência relacionada à saúde;verificar a existência de políticas públicas para os moradores de rua.

As entrevistas aconteceram em forma de conversas com perguntas semi-abertas. Os moradores de rua inicialmente ficavam constrangidos e, alguns dos que conversamos não nos permitiram que fossem relatadas suas histórias. O setor de assistência social está no momento em pesquisa para estimar qual o número de cidadãos vivem em situação de rua. Dentre os abordados, descrevemos quatro relatos e memórias dos moradores de rua da Cidade de Criciúma SC.

\section{Qualidade de vida}

A qualidade de vida para muitos estudiosos é abordada como direito a uma boa educação, bem estar e como sinônimo de saúde.

Ferreira (2008), afirma que o termo qualidade de vida surgiu pela primeira vez nos Estados Unidos após a segunda guerra mundial (1939 a 1945), relatando que os bens materiais como carros, casas entre outros influenciavam na qualidade de vida. Ainda neste tempo, o termo qualidade de vida era relacionado ao "dia de amanhã", influenciando as pessoas a pensarem no que deixariam para seus filhos e qual seria a qualidade de vida deles. Segundo o autor, já na década de 1980 o termo qualidade de vida foi utilizado como sinônimo de auto-estima, bem estar, felicidade e habilidade de cuidar de si mesmo.

Segundo Leal (2008), a qualidade de vida está relacionada com a percepção que cada indivíduo tem dentro de si, dos outros e do mundo que o rodeia. Qualidade de vida diz respeito a como as pessoas vivem, envolvendo saúde, educação, transporte, moradia, trabalho entre outros. Para Cardoso (1999), a qualidade de vida é "a sensação de bem-estar do indivíduo", esta sensação é proporcionada pela satisfação de condições tanto objetivas - a renda, emprego, objetos possuídos, qualidade de habitação -quanto às condições subjetivas como segurança, privacidade, reconhecimento e afeto.A qualidade de vida envolve a maneira pela qual o indivíduo interage, levando-se em conta sua individualidade e subjetividade, sua interação com o mundo externo, portanto, a maneira como o sujeito é influenciado e influencia.

A qualidade de vida, segundo a Organização Mundial da Saúde (1995), é a percepção do indivíduo de sua posição na vida, no contexto da cultura e sistema de valores em que vive e em relação a suas expectativas, seus padrões e suas preocupações. (Organização Mundial de Saúde - OMS, 1995).

De acordo com TANI (2002), não há dúvida que determinados aspectos da vida como a felicidade, amor e liberdade - mesmo sendo sentimentos e valores difíceis de serem compreendidos -, são absolutamente relevantes, acontecendo o mesmo com a qualidade de vida.

Leal (2008), na tentativa de ampliar a discussão sobre os elementos envolvidos 
na qualidade de vida, aponta que ela está envolvida com os aspectos culturais, econômicos e psicológicos. Em relação à cultura está ligada à educação e à infância. Nesta fase os pais transmitem aos filhos hábitos e valores próprios ligados ao meio cultural em que estão inseridos como tipos de alimentação, hábitos religiosos entre outros. Essa realidade influencia na personalidade da criança que quando adulta provavelmente terá estilos de vida parecidos com os de seus pais.A mídia também exerce uma grande influência no nível cultural, publicando e mostrando à população o que é indispensável para o indivíduo ter qualidade de vida. Por meio de publicidade a mídia impõe necessidades em nome da qualidade de vida.

A autora ressalta que na perspectiva econômica a qualidade de vida está ligada aos bens materiais que cada indivíduo possui. Muitas pessoas associam qualidade de vida ao ter ou não dinheiro, ligando a qualidade de vida ao luxo e ao que podem ter e fazer a partir do que possuem financeiramente.

Em relação aos aspectos psicológicos, Leal (2008) aponta a qualidade de vida como dependente da personalidade de cada pessoa, ela é avaliada como auto estima, respeito pelo seu semelhante, aproveitar os momentos de felicidade, ter boas expectativas em relação ao futuro além de ajudar o próximo. A qualidade de vida depende do indivíduo e, da sua interação com os outros e com a sociedade. Os critérios para avaliar a qualidade de vida neste sentido são, por exemplo, a atividade profissional, a capacidade para realizar atividades diárias, a mobilidade, a saúde e, aspectos que cada indivíduo considera contribuir para a sua felicidade.

\section{Compreender as Políticas Públicas para os moradores de rua}

Os moradores de rua têm direito constitucional às políticas públicas que os contemplem, sendo eles, sofredores de violação de seus direitos humanos. A Política Nacional para Inclusão Social da População em Situação de rua de 2008 diz que para propor políticas públicas é necessário identificar estratégias como: direitos humanos, trabalho e emprego, desenvolvimento urbano/habitação, assistência social, saúde e educação.

Os direitos constitucionais a seguir é o que preconiza o documento oficial "Política Nacional para inclusão social da população em situação de rua." do governo federal.

Dentro dos Direitos Humanos se faz necessário a capacitação das forças policiais para que atendam com melhor preparação a população em situação de rua, bem como o fortalecimento da ouvidoria de denúncias e violações dos direitos humanos, combater os crimes e os atos de violência cometidos contra os moradores deixando a rua com maior segurança. (BRASIL, 2008).

Segundo Costa (apud BULLA, et al, 2004, p. 129), "embora os serviços de segurança sejam eventualmente buscados, eles são vistos pela população de rua com desconfiança, o que pode significar uma condição de conformidade ou 'anestesia' em relação à violência".

No que diz respeito ao trabalho e à educação é necessário capacitação, qualificação e requalificação dos moradores de rua, além de incentivá-los ao trabalho e, principalmente, a garantia dos seus direitos trabalhistas e a aposentadoria. (BRASIL, 2008). 
Para o Desenvolvimento Urbano/ Habitação é essencial à criação de alternativas de moradia e projetos habitacionais com financiamento do Governo Federal, alternativas de moradias compartilhadas articulando os governos Estaduais e Municipais. Garantia dos meios de sobrevivência como proximidade aos locais de trabalho, facilidade de transporte, entre outros. (BRASIL, 2008).

[...] no que se refere ao direito à moradia, uma política pública voltada a esse público precisa garantir ofertas habitacionais diferenciadas, ou seja, precisa identificar as pessoas em situação de rua como parte de seu público, propondo alternativas de moradia adequadas a sua realidade. (COSTA, 2005, p. 7)

Dentro da assistência social se faz necessário a inclusão dos moradores de rua, sejam eles adultos ou jovens, no Cadastro Único do Governo Federal, subsidiando a elaboração e implementação de políticas públicas sociais, e os adolescentes ao Programa de Erradicação do Trabalho Infantil. Que se tenha uma boa estrutura das redes de acolhidas como os albergues e promoção de novas oportunidades de inclusão e trabalho (BRASIL, 2008).

Na educação são imprescindíveis à igualdade social, especialmente com relação aos moradores de rua, incentivos à alfabetização, com materiais escolares e uniformes gratuitos e alimentação, permanência nas escolas de acordo com a realidade das pessoas moradoras de rua, flexibilidade de documentos pessoais e residenciais. $\mathrm{E}$, principalmente, da inclusão do tema população de rua, bem como suas causas e consequências, debatendo o assunto em todas as redes de ensino do país (BRASIL, 2008).
No aspecto da saúde o fortalecimento das promoções à saúde no Programa Saúde da Família sem Domicilio com ênfase na prevenção de doenças sexualmente transmissíveis/AIDS, tuberculose, hanseníase, hipertensão arterial entre outras. É necessária a atenção a saúde mental dos moradores de rua, principalmente com transtornos resultantes ao uso de drogas como o álcool e entorpecentes e atendimentos em Centros Psicossocial (CAPS I,II,II E AD), Sistema Único de Saúde (SUS), Atendimentos de Urgência (SAMU) entre outros. De acordo com Costa (2005),

pode-se dizer que o maior problema na área da saúde que atinge essa população está no campo das doenças mentais. Compõem esse quadro doenças como a dependência de substâncias psicoativas e as neuroses e psicoses, de tal modo que a grande maioria de pessoas que vive nas ruas tem algum tipo de sofrimento psíquico. (COSTA, 2005, p. 8)

Quem vive nas ruas, infelizmente fica invisível aos olhos das redes de saúde. Muitos moradores acabam morrendo nas ruas por falta de acesso aos serviços de saúde.

\section{Caracterização da população em situação de rua}

A população de rua, tendo situações de vidas precárias, utiliza das ruas como moradia e abrigo, pois fica abaixo da pirâmide do capitalismo, jáque nem todos conseguirão um trabalho digno sendo excluídos da sociedade.

[...] a questão do morador de rua é algo muito pertinente na sociedade e que 
merece receber um outro olhar clínico. Uma vez que, a pessoa moradora de rua,passa e se sujeita a uma situação de extrema vulnerabilidade social, no limite da exclusão social, da desfiliação social e da pobreza, sem ter a garantia do mínimo para sua subsistência, além de uma série de outras questões sociais, políticas e econômicas. (OLIVEIRA et al. 2009, p.2)

A população de rua é composta por indivíduos de diferentes realidades, mas que comungam da condição de pobreza sem pertencer à sociedade formal. Por diferentes ou parecidos motivos como a perda de emprego, uso de drogas, rompimentos de laços afetivos, muitos perderam a expectativa de vida e se refugiaram nas ruas (COSTA, 2005).

Essa realidade é característica do processo de exclusão social que existe no Brasil neste início de milênio. A exclusão social, que passamos a conhecer, tem origens econômicas, já referidas, mas caracteriza-se, também, pela falta de pertencimento social, falta de perspectivas, dificuldade de acesso à informação e perda de auto-estima. Acarreta consequências na saúde geral das pessoas, em especial a saúde mental, relaciona-se com o mundo do tráfico de drogas, relativiza valores e estabelece padrões e perspectivas de emancipação social muito restritos. (COSTA, 2005, p. 3)

Como os moradores de rua existem também indivíduos que, a procura de um melhor emprego, encontram-se obrigados a viver na rua até que consigam um lar ou voltar para sua casa. Na mesma situação também estão os chamados de andarilhos, que são aqueles que vão de cidades a cidades, geralmente sozinhos (COSTA, 2005).

Os moradores de rua em Criciúma encontram-se em sua maior parte nas praças da cidade e, ao longo do dia, alguns trabaIham nos sinais de trânsito fazendo malabarismos e procurando materiais recicláveis. Existem também os que andam na cidade pedindo ajuda em dinheiro e alimentação.

Em uma casa de acolhida, os moradores de rua podem pernoitar somente quando não estão sobre efeito da droga e do álcool. Além de passar a noite, na casa é oferecido banho e alimentação. Quando o morador de rua tem o objetivo de mudar sua situação e consegue emprego, a casa permite que fique morando temporariamente até receber seu primeiro pagamento.

Os moradores de rua de Criciúma são abordados três vezes por semana na região central e duas vezes por semana nos bairros da cidade pelo Centro de Atenção Psicossocial (CAPS). Eles recebem tratamento quando estão doentes. Nas ruas e praças eles podem contar com a orientação de um agente do sistema social.

Na cidade o Centro de Referência Especializado de Assistência Social (CREAS) atende os moradores de rua desenvolvendo abordagens por meio de uma ação integrada entre órgãos governamentais e não governamentais, os encaminhando para unidades de urgência e emergência favorecendo aos moradores a superação das situações de risco com programas educativos e promoção social. Ainda não se sabe qual o número dos moradores que vivem nesta situação, mas a Prefeitura Municipal de Criciúma em conjunto com CREAS está iniciando uma pesquisa para levantar esses dados.

\section{Os moradores de rua por eles mesmos: descobertas das entrevistas}

Com 6 anos, o morador 1 foi para as ruas levado por sua mãe. Oitenta por cento 
de sua família também vive em situação de rua. O morador passou sua infância nas ruas e em abrigos. Quando seu pai descobriu seu paradeiro o resgatou e enquanto vivia com seu pai fugia varias vezes para as ruas. O morador 1 viveu com seu pai até os doze anos.

Enquanto estava nas ruas cometeu um crime e voltou para o abrigo ficando lá até completar a maioridade, quando saiu voltou a viver em situação de rua. Hoje com 23 anos está sem vínculo familiar, apesar de ter na cidade familiares na mesma situação.

O morador nunca dormiu em praças, ele sempre procura casas e construções abandonadas. No albergue passa as noites somente quando está com sua saúde debilitada. Quando acorda vai à busca de alimento e droga, o morador é dependente de crack, muitas vezes chegou a furtar para sustentar seu vicio.

Como foi criado nas ruas, não sente falta de uma casa, pois ele diz ter dificuldades para se adaptar. Quando precisa de banho vai até a casa do "senhor do sistema social", o qual respeita muito e o considera da família, pois ele o acompanha desde criança e algumas vezes o levou para a sua casa. O morador diz que não gosta de ficar sujo e procura estar sempre bem arrumado.

O morador 1 frequentou a escola até o terceiro ano do ensino fundamental. Já nos projetos em Criciúma participou de rap, dança e diz gostar muito de basquetebol. Seu lazer é caminhar e conversar com os amigos. O morador tem objetivo de mudar sua situação, mas o crack é "uma droga que o domina". Ele já tentou parar com o vício - inclusive procurou ajuda em clínica para tentar se recuperar - e diz querer um emprego e um carro próprio.
O morador 2 tem 51 anos e dois filhos. Diz que decidiu ir para as ruas quando aconteceu a separação do seu primeiro casamento. Ele é um dos moradores mais antigos de Criciúma, vivendo nas ruas há pouco mais de vinte anos. Nas ruas dormia em casas abandonadas, construções e caminhava durante o dia, porém quase sempre acompanhado dos seus leais cachorros.

O morador conta que sofreu muito com o frio e com a fome. Emocionado lembrou-se das vezes que "acordava com a barriga roncando e com muita sede". Os donos de padarias e restaurantes sempre o ajudam com alimentação e ele não se esquece de pedir comida para os seus cachorros.

Nas ruas ele conheceu sua segunda esposa, apaixonada o convidou para morar com ela. No início do namoro, por escolha, decidiu continuar nas ruas e quando casaram dormia em sua nova casa, mas continuava caminhando com seus cachorros pela cidade durante o dia.

O morador 2 ficou casado por pouco tempo. Contou que sua segunda esposa faleceu a cerca de seis meses. Sua esposa tinha dois filhos, um deles morava sozinho, mas tinha uma filha que morava com eles; por respeito à menina, procurou o outro filho de sua esposa e pediu que cuidasse dela. Desde então o morador 2 voltou a morar nas ruas. Hoje, aposentado tem um lugar para morar cedido por um tenente do Exército.

Como lazer o morador 2 faz sua caminhada diária. Lembra que na escola o que mais gostava de praticar era o futebol. Nas ruas de Criciúma usa do seu tempo livre para cuidar de seus cachorros. O morador 2 diz que nunca usou drogas e fica muito triste quando vê a situação em que ficam os outros moradores usuários. Ele faz uso 
apenas do álcool. O que mais sente falta é dos seus antigos amigos e fala com orgulho que sua família sempre o apoiou. Hoje, o morador 2 está muito orgulhoso de ter seu cantinho e ainda faz questão de convidar as pessoas amigas para visitá-lo e jantar em seu novo lar.

O morador 3, de 28 anos, foi para as ruas quando sua mãe faleceu. Veio de outra cidade e hoje vive nas ruas de Criciúma. É um dos moradores com menos tempo em situação de rua,está vivendo nesta situação há cerca de dois meses.

Vivendo nas ruas sofreu com agressões da polícia e diz que muitas vezes o trataram como "bicho". Explicita que algumas pessoas de Criciúma o olham com discriminação, mas a maioria o trata com carinho e respeito e sempre tem alguém que o ajuda com a alimentação.

Quando ia para a escola, o que mais gostava de praticar nas aulas de Educação Física era o futebol. Hoje o que faz como lazer é jogar sinuca nos bares da cidade.

O morador 3 diz ter deixado em sua cidade natal seu filho e sua família e que mantém pouco contato com eles. Com pouco tempo nas ruas espera receber seu primeiro salário para poder alugar um quarto e sair das ruas. Ele diz que "não é fácil viver em situação de extrema pobreza". O que mais sente falta é de uma casa, um lugar para poder tomar banho todos os dias e dormir tranquilamente e, principalmente, de seu filho e sua mãe.

O morador de Rua 4, de 32 anos, que veio de outra cidade, diz que decidiu ir para as ruas quando sua avó, que o criou, faleceu. Com a morte dela voltou a usar drogas e foi internado, quando saiu da clínica de recuperação encontrou sua casa completamente vazia. Além dos móveis, sua esposa levou o dinheiro que o morador tinha e seus dois filhos. A partir da perda dos laços familiares largou tudo e foi viver nas ruas, disse que "iria fazer tudo o que nunca tinha feito e que tudo o que aconteceu, não era culpa de ninguém, porque foi ele o único responsável pela sua derrota".

O morador 4 foi para as ruas de Criciúma dormindo quase todas as noites em um mesmo lugar. Durante cinco anos sustentava seu vício pedindo dinheiro nos sinais de trânsito e procurando materiais recicláveis para vender. As pessoas e o comercio próximo ao lugar onde passava as noites sempre o ajudaram, pois ao longo desse tempo "Deus o guardou de matar e roubar". O morador disse que nunca precisou roubar nada de ninguém porque sempre soube que "tudo o que temos foi resultado do nosso esforço e jamais roubaria ou tiraria de alguém nenhum pertence, mesmo que para ele um celular, uma jóia não significasse nada, mas sabia que para os donos poderia significar tudo".

O morador 4 contou que passou muitas dificuldades na rua como o frio e a chuva. Em um inverno, quando pedia dinheiro nos sinais de trânsito, começou a chover muito e com muita dor e frio foi até um lugar que estava abandonado onde guardava suas roupas e cobertores. Infelizmente, naquele dia seus pertences foram roubados. Andando pelas ruas da região chorava muito e pedia a Deus que mandasse alguém para ajudá-lo, em pouco tempo um carro parou ao seu lado e ofereceu comida, roupa seca e cobertores, naquele instante soube que Deus o havia escutado.

$\mathrm{Na}$ opinião do morador, as ruas de Criciúma não são seguras. Entre os moradores há um respeito, mas tem policiais que vestem a farda e se sentem "super 
heróis". O morador foi agredido por um policial porque estava pedindo ajuda no sinal de trânsito e até hoje tem as marcas da agressão.

O único esporte que o morador praticava era "correr da polícia para não apanhar", ele não tinha nenhum tipo de lazer.As atividades que fazia eram apenas para sustentar seu vício. O morador ainda lembra-se das suas aulas de Educação Física e diz que o que mais gostava era quando praticava o basquetebol. Por ser muito tímido naquela época não participava das aulas de dança na escola, "hoje a rua ensinou a perder a timidez".

O morador de Rua 4 no momento está com um emprego e a procura de um lugar para morar. Tem medo de que se não conseguir um lar tenha que voltar a viver nas ruas. Não tem intenção de voltar à sua cidade, mas já entrou em contato com sua família que não via e falava há cinco anos por vergonha de sua situação. No momento vive na Casa de passagem de Criciúma e anteriormente em uma casa de recuperação que foi apresentada por um jovem que falou de Deus e o ajudou a mudar sua situação.

O que eu mais sinto falta é da minha dignidade, porque eu era respeitado e bem visto na minha cidade. Eu não era rico mais tinha o suficiente para sustentar minha família. A maioria da sociedade te exclui e te trata como bicho. Tem pessoas que olham pra tua aparência e tem alguns aqui que olham para o teu coração, viam em mim o que eu era capaz. Hoje em dia é difícil encontrar pessoas assim, que olham para o teu coração (Morador 4 - Criciúma - Santa Catarina).

Muitas vezes quando não estava sobre o efeito do crack, o morador disse que tentou mudar sua situação, "mas o crack permite que se enxergue o que está fora da gaiola, mas em todas as gaiolas existem também as cercas que impedem de sair".

\section{CONSIDERAÇÕES FINAIS}

$\mathrm{Na}$ visão de alguns autores a qualidade de vida está relacionada aos bens materiais, boa alimentação, sensação de bem estar, renda e emprego, segurança, qualidade de habitação entre outros. Assistir um filme, atividades físicas, caminhadas, atividades de livre escolha são apresentadas como lazer.

Conhecidos também como andarilhos e mendigos, os moradores de Rua de Criciúma não possuem quase nenhum bem material, dificilmente conseguem fazer uma boa alimentação e a grande maioria não conta com emprego e renda. $\mathrm{A}$ segurança das ruas nem sempre é um local apropriado, muitos não conseguem dormir tranquilamente. Quando se fala em habitação, dormir nas ruas, no frio e chuva não se pode considerar uma boa qualidade de vida.

Os moradores de rua de Criciúma batem papo com os amigos, participam de projetos sociais em que o esporte está inserido e há casos dos que cuidam dos animais como práticas de lazer.

Nas entrevistas apresentadas a caminhada é o lazer de muitos. A caminhada para alguns moradores de rua é um prazer em busca da solidão e um contentamento de estar consigo mesmo.

A população em situação de rua está relacionada ao capitalismo que exclui, que tem o poder de dominação sendo o responsável pela desigualdade social. MiIhares de pessoas se encontram vivendo em 
condições sub-humanas, sem direitos à moradia, à alimentação, ao emprego, ficando fora do alcance para esta população o direito ao lazer e uma boa qualidade de vida. Os moradores de rua estão nesta situação porque são vítimas do sistema capitalista que explora e não respeita o indivíduo, porque romperam laços familiares, porque perderam a vontade de lutar, porque são dominados pela droga e álcool.

Os moradores de Rua vivem em situação de exclusão e vulnerabilidade social, as ruas para eles, são espaços de moradia e sobrevivência.

O Brasil precisa implantar políticas públicas legitimadas que atendam as reais necessidades desta população. É importante que os moradores de Rua se reconheçam cidadãos de direitos e que, sobretudo tomem posse de sua dignidade.

Conhecer a população em situação de rua é o primeiro passo para a mudança social.

\section{REFERÊNCIAS}

BRASIL. Política Nacional para inclusão social da população em situação de rua. 2008, Brasília.

MINISTÉRIO DA SAÚDE. Secretaria de Atenção à Saúde. Departamento de Atenção Básica. Manual sobre o cuidado à saúde junto a população em situação de rua / Ministério da Saúde. Secretaria de Atenção à Saúde. Departamento de Atenção Básica. - Brasília : Ministério da Saúde, 2012.

BERTUOL, Fernanda P.Qualidade de vida, subjetividade e interação. In: II CONGRESSO DE EDUCAÇÃO DOM BOSCO, 2006, Curitiba. p. 94 - 100.

CARDOSO, et al. Qualidade de vida e trabalho: uma articulação possível. In: Série Saúde mental e trabalho. São Paulo: Casa do Psicólogo, 1999.

COSTA, Ana Paula M. População em situação de rua: contextualização e caracterização*. Revista Virtual Textos

\& Contextos, RS, n. , p.1-15, dez. 2005.

Estudos do lazer:uma introdução. Campinas: Autores Associados, 2006. Disponível em: <http://www.kilibro.com/book/ preview/41106_estudos-do-lazer $>$. Acesso em: 04 jun. 2013.

FERREIRA, Brunno Elias. O conceito qualidade de vida inserido na atividade física: reflexão sobre concepções e evidências. Efdesportes, Buenos Aires, n.,p.1-1, jul. 2008.

LEAL, Manuela Silva. Reavaliar o conceito de qualidade de vida. (Dissertação de mestrado). Açores (Portugal): Universidade dos Açores. 2008.

LESSA, Sérgio; TONET, Ivo. Introdução à filosofia de Marx. São Paulo: Expressão Popular, 2004.

MUNHOZ, Dércio G. Economia aplicada: técnicas de pesquisa e análise econômica. Brasília: Unb, 1989.

OLIVEIRA, João. Pluralizando tradições etnográficas: sobre um certo mal-estar na Antropologia. In. Cadernos do LEME, Campina Grande, vol.1, n1, p. 2-27. Jan/jul. 2009.

O PAPEL DAS POLÍTICAS PÚBLICAS NO DESENVOLVIMENTO LOCAL E NA TRANSFORMAÇÃO DA REALIDADE.

Ba: Aatr, 2002. Disponível em: < http://www.fit.br/home/link/texto/ politicas_publicas.pdf $>$. Acesso em: 31 out. 2012.

OGATA, Alberto; SIMURRO, Sâmia. Guia prático de qualidade de vida. Rio de Janeiro: Elsevier, 2009. 
ORGANIZAÇÃO MUNDIAL DE SAÚDE. 1995. "tHeWorLdHeaLtHorGanization quaLityoFLiFeassessMent (WHoqoL): Position PaPerFroMtHeWorLd HeaLtHorGanization". soCiaLsCienCe and MediCine. v.41, n.10, P.403-409.
TANI, G. Esporte, educação e qualidade de vida. In W.W. Moreira e R. Simões (Orgs.).Esporte como fator de qualidade de vida. Piracicaba: Editora UNIMEP, 2002.

REPORTS AND MEMORIES OF STREETRESIDENTS: studies on quality of life and public policies for the population living in the street situation Criciúma/SC.

\begin{abstract}
This work deals with the situation of those who are in the condition of homeless people. Organized a qualitative approach based on the literature review that aimed to discuss the quality of life and public policies related to homeless people. Interviews were conducted with homeless people in order to understand what is the quality of life of the homeless. Why lose family ties, jobs and so many other reasons like drugs, alcoholism, social discrimination, dignity, this population utilizes the streets as housing and shelter.
\end{abstract}

Keywords: Street people; Quality of life; Public policy.

Recebido em: agosto/2013

Aprovado em: novembro/2013 